\title{
Outcomes of 25 Gynecologic Cancer Patients with Brain Metastasis: A Single Center Experience
}

\author{
Serhat Comert ${ }^{1 *}$, Mehmet Nur Altınörs ${ }^{2}$ \\ ${ }^{1}$ Department of Neurosurgery, Yenimahalle Training and Research Hospital, Ankara, Turkey \\ ${ }^{2}$ Department of Neurosurgery, School of Medicine, Başkent University, Ankara, Turkey
}

*Corresponding Author: Serhat Comert, Department of Neurosurgery, Yenimahalle Training and Research Hospital, Yeni Batı Mah. 2026. Cad. 2367. Sok. No: 406560 Yenimahalle, Ankara, Turkey.

\begin{abstract}
Gynecologic malignancy is the second most common cancer in elderly women. These cancers usually spread locally at first, and distant metastatic sites. The brain is not a usual site of metastatic involvement. However, we present 25 gynecologic cancer cases with brain metastasis. The study included 25 cases with various gynecologic malignancies that were retrospectively analyzed. Therapeutic modalities, survival and time between the initial surgery and brain metastasis were recorded. Mean survival was 48.5 months for 25 patients with ovarian cancer versus 32.4 months in those with other gynecological cancers. At the time of brain metastasis, the CA-125 level was elevated in all the patients, except 4 whom had cervical cancer. Mean $C A-125$ level was $202 I U \mathrm{~mL}-1$. There were not any differences in mean overall survival between the patients who underwent surgical resection and those received medical treatment. Brain metastasis can occur in all gynecologic cancers and has a poor prognosis, despite multimodal treatment.
\end{abstract}

Keywords: Gynecologic cancers, brain metastasis, ovarian carcinoma, cervical carcinoma, endometrial carcinoma

\section{INTRODUCTION}

Brain metastasis is common in patients with leukemia, lymphoma, lung cancer and breast cancer; however, metastasis to the brain in patients with gynecologic malignancies is uncommon, except for choriocarcinoma $[1,2]$. Epithelial ovarian carcinoma (EOC) is one of the most common gynecologic malignancies and has similar clinical prognosis as primary peritoneal carcinoma (PPC) [3]. Brain metastasis in EOC and PPC cases are rare and usually present as a late manifestation in patients with prolonged survival. The incidence of brain metastasis in EOC ranges from $0.29 \%$ to 5\% [4-7]. Only 2 case of primary peritoneal adenocarcinoma metastasis to the brain have been reported [8, 9]. Endometrial adenocarcinoma is the most common gynecologic malignancy and has a low incidence of metastasis to the brain; ranging from $0.3 \%$ to $1.4 \%[10,11]$.

Metastatic disease to the CNS from other gynecological malignancies, such as cervical cancer, uterine sarcomas and vulvar cancer is extremely rare. For example, only a few reports of brain metastasis in vulvar carcinoma patients have been published in the English language literature $[12,13]$. We report the radiological findings, treatment modalities, outcomes, and survival in 25 gynecological cancer patients with metastasis to the brain that were treated between 2007 and 2017 at the Başkent University Department of Gynecologic Oncology.

\section{Materials ANd Methods}

This retrospective study included gynecological cancer patients with metastasis to the brain that were treated at Başkent University between January 2007 and January 2017. The retrospective design of the study eliminated the necessity of ethical committee approval. Pathologic classification of the cancers, treatment regimens, time from onset of disease to detection of brain metastasis, extracranial metastasis and time of occurrence, changes in the CA-125 level, and overall survival (OS) are provided, along with brain imaging findings. Additionally, survival and factors involved in prognosis are discussed. SPSS v.17 was used for statistical analysis. Dichotomous variables were 
analyzed using the chi-square test and numeric variables were analyzed using the t-test. $\mathrm{P}$ values $<0.05$ were considered statistically significant.

\section{Results}

\subsection{Ovarian Carcinoma}

Among 657 patients with EOC, 11 (mean age: 57 years; range: 45-74 years) developed brain metastasis. In all, 8 of these 11 patients had serous adenocarcinoma and 2 had clear cell adenocarcinoma. All 11 patients underwent cytoreductive surgery performed by an experienced gynecologic oncology team. All 9 patients with serous adenocarcinoma had stage IV cancer, and received paclitaxel and carboplatin as first-line chemotherapy. Only 2 of the serous adenocarcinoma patients achieved remission without recurrence during 12 months of follow-up; the 9 other patients had disease free survival (DFS) of 9 months. Other chemotherapeutic agents, including liposomal doxorubicin, gemcitabine, topotecan, weekly

Table1. Features of patients with gynecologic cancers metastasize to brain

\begin{tabular}{|c|c|c|c|c|}
\hline $\begin{array}{c}\text { Type of } \\
\text { gynecological } \\
\text { malignancies }\end{array}$ & $\begin{array}{l}\text { Number of sites } \\
\text { involved in CNS }\end{array}$ & $\begin{array}{c}\text { Operation } \\
\text { status }\end{array}$ & $\begin{array}{l}\text { Radiotherapy status } \\
\text { for brain metastasis }\end{array}$ & $\begin{array}{c}\text { Interval between initial and } \\
\text { second diagnosis / Survival } \\
\text { after brain metastasis }\end{array}$ \\
\hline $\begin{array}{c}\text { Patient A Ovarian } \\
\text { serous carcinoma }\end{array}$ & 2 sites & NA & NA & $34 \mathrm{~m} / 4 \mathrm{~m}$ \\
\hline $\begin{array}{l}\text { Patient B Ovarian } \\
\text { serous carcinoma }\end{array}$ & 1 site & Operated & RT & $26 \mathrm{~m} / 9 \mathrm{~m}$ (alive) \\
\hline $\begin{array}{l}\text { Patient C Ovarian } \\
\text { serous carcinoma }\end{array}$ & 2 sites & Operated & RT & $72 \mathrm{~m} / 6 \mathrm{~m}$ \\
\hline $\begin{array}{l}\text { Patient D Ovarian } \\
\text { serous carcinoma }\end{array}$ & 2 sites & Operated & RT & $28 \mathrm{~m} / 4 \mathrm{~m}$ \\
\hline $\begin{array}{l}\text { Patient E Ovarian } \\
\text { serous carcinoma }\end{array}$ & 1 site & NA & NA & $36 \mathrm{~m} / 7 \mathrm{~d}$ \\
\hline $\begin{array}{l}\text { Patient F Ovarian } \\
\text { clear cell carcinoma }\end{array}$ & 4 sites & NA & NA & $35 \mathrm{~m} / 2 \mathrm{~m}$ \\
\hline $\begin{array}{l}\text { Malignant mixed } \\
\text { mullerian tumor }\end{array}$ & 2 sites & NA & NA & $5 \mathrm{~m} / 2 \mathrm{~m}$ \\
\hline $\begin{array}{c}\text { Endometrial carcinoma } \\
\text { (Endometroid) }\end{array}$ & 2 sites & $\begin{array}{l}\text { Only } \\
\text { biopsy }\end{array}$ & RT & $29 \mathrm{~m} / 30 \mathrm{~m}$ (alive) \\
\hline $\begin{array}{c}\text { Endometrial carcinoma } \\
\text { (Serous) }\end{array}$ & 1 site & NA & NA & $2 \mathrm{~m} / 5 \mathrm{~m}$ \\
\hline $\begin{array}{c}\text { Primary Peritoneal } \\
\text { carcinoma }\end{array}$ & 3 sites & NA & NA & $13 \mathrm{~m} / 2 \mathrm{~m}$ \\
\hline Cervical carcinoma & 1 site & Operated & RT & $4 \mathrm{~m} / 1 \mathrm{~m}$ \\
\hline Vulvar carcinoma & 4 sites & NA & NA & $36 \mathrm{~m} / 12 \mathrm{~d}$ \\
\hline
\end{tabular}

(NA: Not applicable, RT: Radiotherapy, $m:$ Months, $d$ : Days)

\subsection{Other Gynecologic Malignancies}

In all, 368 patients with endometrial cancer underwent various surgical and medical treatments during the study period, 4 of which developed brain metastasis; histopathological types were endometrioid and serous papillary adenocarcinoma. Both patients underwent initial paclitaxel, and oral tamoxifen, were used one by one in the mentioned order until recurrence occured or an increase in CA-125 was observed.

Mean Ca-125 level was $237 \mathrm{IU} \mathrm{mL}^{-1}$ (range: 2$735 \mathrm{IU} \mathrm{mL}^{-1}$ ) at the time CNS metastasis was noted. Mean survival after cytoreduction in the stage IV cancer patients was 43.9 months (range: 27-79 months); following brain metastasis mean survival was limited to 2.78 months (range: 0-9 months), regardless of the therapy used. The four patients that underwent surgical resection due to cranial metastasis had OS of 4.3 months following surgery. The other 3 patients opted for medical treatment and had OS of 2.2 months. Among the 3 patients that were surgically treated, 7 had cranial recurrence and again underwent surgery. The difference between treatment regimens was significant $(\mathrm{P}=$ 0.605). Results in the patients with stage III cancer were similar; OS was 39 and 2 months following diagnosis and surgical resection, respectively. staging and cytoreductive surgery. The patient with serous papillary cancer was stage $1 \mathrm{~B}$, grade 3 and the patient with an endometrioid tumor was stage IIIA, grade 3. Both patients received 6 cycles of paclitaxel and carboplatin $\left(175 \mathrm{mg} / \mathrm{m}^{2}\right.$ dose for paclitaxel, AUC 5 dose for carboplatine) following cytoreduction. 
Metastatic disease to the brain occurred with synchronous disseminated abdominal spread in both patients. Elevated CA-125 was observed in these 5 patients $\left(163 \mathrm{IU} \mathrm{mL}^{-1}\right)$ at the time CNS involvement was noted.

During the study period we treated 15 malignant mixed Mullerian tumor (MMMT) patients; 3 patients had stage 4 disease and developed brain metastasis 7 months after initiation of cisplatin and liposomal doxorubicin. Imaging methods, including abdominal and thoracic tomography, showed concomitant lung metastasis and disseminated abdominal spread. Survival following brain metastasis was only 3 months.

One of 256 patients with cervical carcinoma treated during the study period developed cranial metastasis; the patient underwent type-3 hysterectomy, and bilateral pelvic and paraaortic lymph node dissection following $28 \mathrm{~d}$ of chemoradiation with 6 cycles of platin-based chemotherapy. Histopathologic evaluation showed both pelvic and para-aortic lymph nodes consistent with clear cell adenocarcinoma. DFS was 24 months prior to the occurrence of brain metastasis, after which time the patient survived 1 month.

Of the 34 patients with PPC, 3 had brain metastasis during the study period. The treatment administered to this patient was similar to that given to EOC patients; following cytoreductive surgery, chemotherapy consisting of paclitaxel and carboplatin was administered.
DFS was 6 months prior to recurrence. Although the time between the initiation of the therapy and brain metastasis was 13 months, survival after brain metastasis was 1.5 months. Among the 46 patients with vulvar carcinoma, 2 had brain metastasis (squamous cell adenocarcinoma). The patient first underwent surgery at another hospital in 2006, but following recurrence in 2007 vulvectomy and bilateral inguinal lymph node dissection were performed at our hospital. This patient was stage 3 (FIGO). She received 5000 cGy of pelvic radiotherapy concomitant with 3 cycles of cisplatin and doxorubicin. DFS before brain metastasis was 2.3 months; survival after brain metastasis was less than 1 month.

\subsection{Clinical Imaging}

The brain metastases observed in the present study were associated with such clinical manifestations as headache, nausea, vomiting, tinnitus, unconsciousness, dizziness, loss of extremity movement, and ptosis. In most of the patients metastatic disease was diagnosed via magnetic resonance imaging (MRI). Figures 1 and 2 show different sections with brain metastasis of ovarian cancer. Figure 3 shows hystopathologic images of brain metastasis from different kinds of patients. Figures 1 and 2 clearly show that the location of metastatic spread varied (temporal, parietal, frontal lobe, and cerebellum).

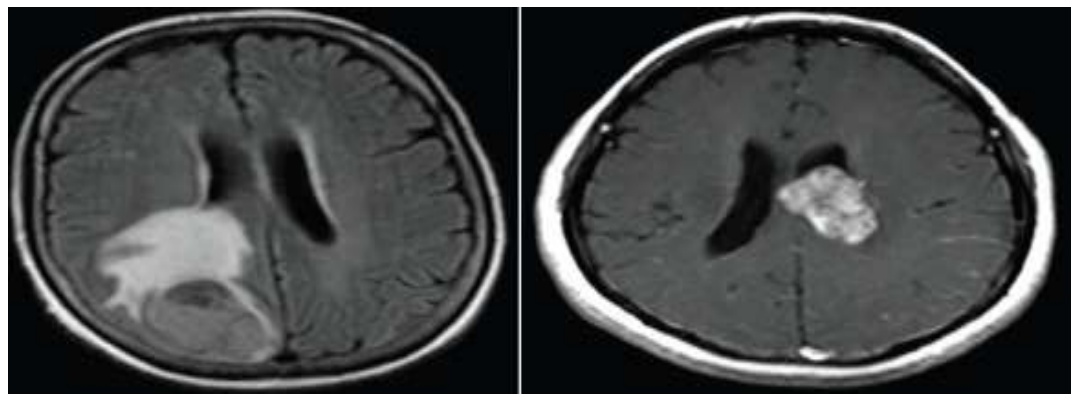

Figure1. Metastasis at different sites with different (coronal and transverse) sections from ovarian cancer patients

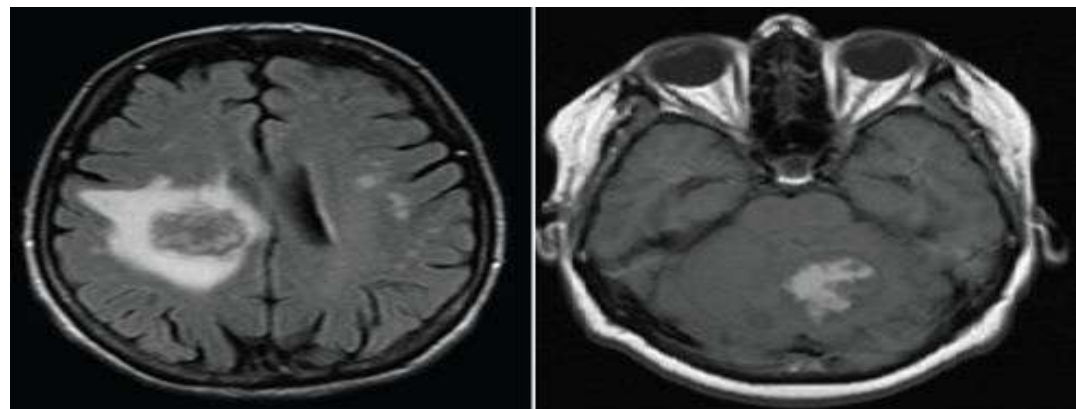

Figure2. Imaging of brain metastasis in other gynecologic malignancies 


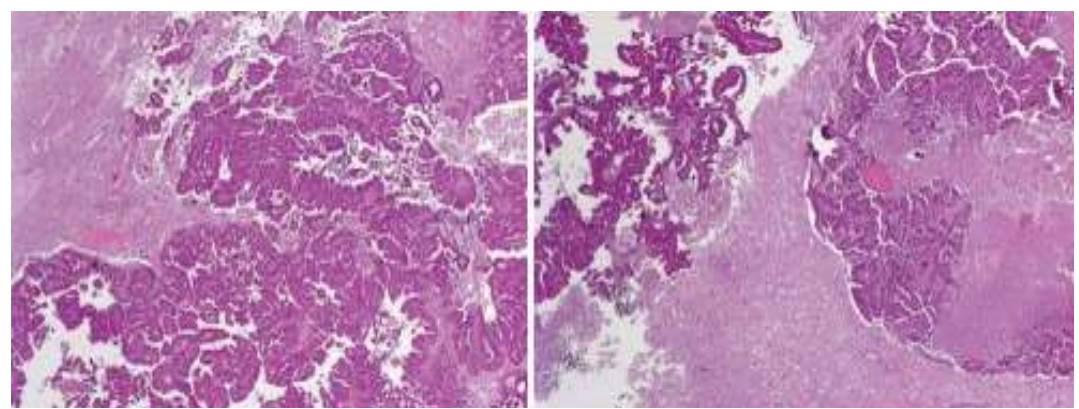

Figure3. Histopathologic images of brain metastasis from different types of patients with different magnification values

While single intracranial metastasis occurred in 14 patients, multiple intracranial metastasis occurred in 11 patients. In 4 patients with ovarian cancer, 2 with cervical cancer, and 5 with endometrial cancer there was no recurrence other than brain involvement based on abdominal and thoracic screening. The other patients had multiple abdominal metastasis. Among these 5 patients that received radiation treatment, only 1 also received chemotherapy. There weren't any differences in mean OS between the patients with brain metastasis that underwent surgical resection, medical therapy, and radiotherapy $(\mathrm{P}=0.859)$, which was 2.2 months for all 25 patients. The patient with endometrial cancer and multiple intracranial metastasis underwent stereotaxic biopsy following gamma-knife radiotherapy, and was alive 19 months post treatment. In total, 11 patients with multiple intracranial metastasis and 6 with single intracranial metastasis were given palliative therapy.

\section{DisCuSSION}

The incidence of brain metastasis in clinical series of gynecological cancers is approximately $1 \%[14,15]$. In the present study 9 of 657 patients with EOC developed brain metastasis $(1.3 \%)$. The mean age of patients with EOC and brain metastasis varied from 50.4 to 59.3 years (range: 19-77 years) in different studies and 3\% of these patients were stage III and IV [16]. In the present study 11 patients with EOC had serous adenocarcinoma - the most frequently encountered type, which is similar to previous findings [16]. Mean age of these 11 patients was 60 years (range: 45-74 year); all but 3 had advanced stage disease (stage III and IV), -7 had serous adenocarcinoma and 1 had clear cell adenocarcinoma.

Some researchers have suggested that the increased incidence of brain metastasis in EOC is related to the effectiveness of chemotherapy [15] or thatcisplatin-based chemotherapy may contribute to an increase in the incidence of CNS involvement $[4,14,17]$. The blood-brain barrier (BBB) is thought to limit delivery of large in size hydrophilic drugs to the brain determining which agents and doses to be used [14]. Additionally, some researchers think that improvement in the efficacy of chemotherapy delays reoccurrence in the abdominal and pelvic cavity, but that the BBB blocks water-soluble cisplatin and lowers the concentration in the CNS, increasing the incidence of brain metastasis [18].

Brain metastasis usually occurs in patients with longer survivals. The maximum time from diagnosis of EOC to brain metastasis was 98 months and the longest survival period after brain metastasis was 7 years $[19,20]$. Tay et al. [21] reported that survival after brain metastasis was up to months, whereas Chen et al. [22] reported that the mean time from initial diagnosis of EOC to brain metastasis was 24.3 months and median survival after the discovery of CNS involvement was 3 months. In the present study mean survival after cytoreduction in stage III-IV cancer patients was 41.9 months (range: 27-79 months), and after brain metastasis was detected mean survival was limited to 2.92 months (rang: 0-6 months), regardless of treatment. Tay et al. [21] suggested that monitoring tumor recurrence based on the serum CA-125 level does not predict metastasis to the brain, as only 1 of 4 cases had elevated CA-125 at the time brain metastasis was diagnosed. All of the EOC patients with brain metastasis in the present study had elevated CA125 (mean: $249 \mathrm{IU} \mathrm{mL}^{-1}$; range: $44-735 \mathrm{IU} \mathrm{mL}^{-}$ ${ }^{1}$ ), as might occur in cases of recurrence in other regions of the body.

The prognosis of patients with brain metastasis is generally very poor without adjuvant treatment, as ranging from none to a few months of survival [20-23].The aim of treatment in patients with brain metastasis should be the 
control of neurologic symptoms and improving quality of life. There are various treatment strategies, including corticosteroids, whole-brain radiotherapy (WBRT), surgery, radiosurgery, and chemotherapy. WBRT is the treatment of choice for most patients with brain metastasis of various malignancies; however, it can cause acute toxicity, such as skin irritation, alopecia, and otitis media.Single metastasis occurs in $43 \%$ of patients with EOC; approximately $50 \%$ of these patients are not surgical candidates because of extra cranial disease or tumor inaccessibility [24].Treating single brain metastasis with surgical resection (with or without WBRT) improves OS [25]. Patchell et al. [26] reported that cases of solitary brain metastasis of any histological type treated with surgical excision plus WBRT had longer DFS, longer OS, and longer duration of functional independence, compared to those treated with WBRT alone. In patients with limited intracranial tumors, focal therapeutic modalities such as gamma-knife radiosurgery (GKS) may replace WBRT or surgery which delivers highdose focal radiation and induces tumor necrosis while delivering minimal radiation to the surrounding normal brain tissue $[23,25]$. In all, 7 patients in the present study underwent surgical resection following WBRT. Patients that weren't treated for metastatic disease because of their medical condition had 2 months of OS, whereas those that underwent surgical resection and radiotherapy had 5 months of OS, and 9 patients was still alive 8 months after the detection of CNS involvement.

\subsection{Other Types of Gynecologic Malignancies}

Few case reports and studies describe patients with endometrial carcinoma and brain metastasis [11]. The incidence of brain metastasis from endometrial carcinoma ranges from $0.3 \%$ to $1.4 \%[10,11]$. The primary mechanism of spread was suggested to be dissemination to the lungs and to the brain via the pulmonary vasculature [27,28]. Many studies report that brain metastasis in endometrial cancer is usually associated with widespread disease, as in 6 patients in the present study [29,30]. Advanced stage, high grade, invasion of the lymphovascular space, and deep myometrial invasion are associated with brain metastasis [10, 27,30,31]. Tumor grade and deep myometrial invasion were correlated in the present study. The mean interval between diagnosis of primary tumor and CNS involvement is ranging from 0 to 52 months $[10,28,32,33]$. These results seem to be compatible with our study as 15.5 months is our time interval for CNS involvement to be found. In the present study mean OS after the diagnosis of brain metastasis was 17.5 months (1 patient was still alive when this report was written). In contrast, 2 cases treated with surgical resection following radiotherapy had long-term OS (82 and 83 months) after the development of brain metastasis [10,33]. One of the patients in the present was still alive (at the time this report was written) 30 months after stereotaxic biopsy following GKS. Chura et al. reported that survival in patients treated with multimodal therapy (WBRT plus surgery, WBRT plus chemotherapy, or WBRT plus surgery and chemotherapy) was longer than in patients treated with WBRT only $(\mathrm{P}=0.0001)$ and in patients that received no treatment $(\mathrm{P}=0.009)$; no difference in OS was observed between the patients treated with WBRT only and those not treated. Other studies also support the survival advantage associated with multimodal therapy $[10,32,34]$.

Brain metastasis from an MMMT of the uterus is very rare. To date, 4 cases of CNS involvement with MMMT metastasis have been reported [35,36]. The pathologic stage at diagnosis seems to be the most reliable predictor of prognosis in MMMT of uterine origin [36]. Surgical excision is considered the most effective treatment, whereas radiotherapy and various combinations of chemotherapy have achieved inconsistent results; however, Wong et al. observed that patients with MMMT of the uterus that received sequential adjuvant therapy — cisplatin and ifosfamide chemotherapy and radiotherapy - had longer survival compared with the control group without any adjuvant therapy [37].The 4 cases mentioned above had mean survival of 2 months after the detection of brain metastasis; complete tumor resection or cranial radiotherapy alone didn't provide a good prognosis [35,36,38]. Even though surgical resection or other mentioned therapies weren't an option for the patient with MMMT in the present study because of her poor medical condition, OS after CNS involvement was 2 months. Based on limited data in the literature, we think that a poor prognosis in MMMT patients with brain metastasis is unavoidable.

Brain metastasis from cervical cancer occurs in $0.4 \%-1.2 \%$ of patients $[39,40]$. Mean OS after initial diagnosis of cervical cancer was 19.2 months and mean survival after diagnosis of brain metastasis ranged from 3 to 8 months [39- 
41]. The treatment of brain metastasis usually involves radiation therapy, surgery, or both, depending on each patient's clinical picture. Generally, surgical excision is used in cases with a solitary lesion or adjacent multiple metastases. Patients with non-adjacent, multiple, or inoperable lesions are usually treated with palliative WBRT $[39,41]$. In the present study's patient the time from initial diagnosis to multiple metastatic CNS involvement was 4 months; nevertheless, survival was only 1 month after the discovery of brain metastasis. Though WBRT was planned, due to the patient's poor medical condition she was given paclitaxel and carboplatin combination chemotherapy.

Brain metastasis from EOC and PPC is considered a rare occurrence. In a series of 24 patients (23 with EOC and 1 with PPC) Ratner et al. reported that OS was 37 months [42]. In the present study there was a significant difference in survival between EOC and PPC patients; OS in the EOC patients was 41.9 months versus 15 months in PPC patients. On the other hand, there was a small difference in survival after brain metastasis between the EOC and PPC patients (2.92 and 2 months, respectively), which was also reported by Ratner et al [42]. Surgical resection of cranial mass was not performed due to her medical condition. As in EOC, survival following brain metastasis in PPC is limited.

Distant spread occurs in $8 \%-12 \%$ of patients with vulvar carcinomas. To date, brain metastasis from vulvar carcinoma has been reported in only 4 cases with different histopathological features. Our patient had squamous cell carcinoma and DFS of 36 months from initial diagnosis to secondary brain metastasis; following brain metastasis the patient survived for $12 \mathrm{~d}$.

\section{CONCLUSION}

Although gynecologic cancers rarely metastasize to the brain, brain metastasis in such cases has a poor prognosis despite combined treatment modalities. Radiation therapy and surgery are effective in only partially removing masses. Unfortunately, on the basis of the known facts and our experience, chemotherapy-especially paclitaxel and carboplatin - functions only as palliation in such patients. Additional research on other chemotherapy regimens and targeted therapies in such patients with brain metastasis is warranted.

\section{CONFLICT OF INTEREST AND FINANCIAL} Disclosure STATEMENTS

The authors declare that they have no conflict of interest. They also declare that they have not engaged in any financial relationship with any company whose product might be affected by the research described or with any company that makes or markets a competing product.

\section{REFERENCES}

[1] Graf AH, Buchberger W, Langmayr H, Schmid KW. Site preference of metastatic tumours of the brain. Virchows Arch. A. Pathol. Anat. 1988;412:493-8.

[2] DeAngelis LM. Managment of brain metastasis. Cancer Invest 1994;12:156-65.

[3] Killacey MA, Davis AR. Papillary serous carcinoma of the peritoneal surface: Matchedcase comparasion with papillary serous ovarian carcinoma. Gynecol Oncol 1993;51:171-4.

[4] Buzzone M, Campore E, Chiara S, Giudici S, Merlini L, Simoni C et al. Cerebral Metastases secondary to ovarian cancer still unusal event. Gynecol Oncol 1993;49:37-40.

[5] Pectasides D, Aravantinos G, Fountzilas G, Kalofonos C, Efstathiou E, Karina Met al. Brain metastases from epitelial ovarian cancer. The Hellenic Cooperative Oncology Group (He COG) experience and rewiev of the literature. Anticancer Res 2005;25:3553-8.

[6] Cohen ZR, Suki D, Weinberg JS, Marmor E, Lang FF, Gershenson DM et al. Brain metastases in patients with ovarian carcinoma: Prognostic factors and outcomes. J Neurooncol 2004;66:313-25.

[7] Geiser JP, Geiser HE. Brain metastases in epitelial ovarian carcinoma. Gynecol Oncol 1995;57:246-9.

[8] Gamal H. Ettebalh, Steven Prier, Bruce A.Werness. Primer peritoneal adenocarcinoma metastatic to brain. Gynecologic Oncology 1997;66:160-3.

[9] Sally W. Nalesnik, Edward R. Kost, Jeffry F, Kevin L. Solitary brain metastasis indicating recurrent primary peritoneal carcinoma. Obstretic and Gynecology 1999;93:844

[10] Cormio G, Lissoni A, Losa G, Zanetta G, Pellegrino A, Mangioni $\mathrm{C}$ et al. Brain metastases from endometrial carcinoma. Gynecol Oncol 1996;61:40-3.

[11] Orru S, Lay G, Dessi M, Murtas R, Deidda MA, Amichetti $M$ et al. Brain metastases from endometrial carcinoma: Report of 3 cases and review of the literature. Tumori 2007;93:1127.

[12] Dursun P, Ayhan A, T.Cagla, Coban G, Kuscu E. Serebellar metastasis in squamous cell 
vulvar carcinoma. Arch Gynecol Obstet 2009;279:69-71.

[13] Vazques JP, Cobo SL, Anton PM, Asado AC, Vidart JA, Coronado $\mathrm{P}$ et al. Brain metastasis and carcinomatous menegitis from vulvar squamous cell carcinoma: Case report Eur J Gynaecol Oncol 2007;28:154-8.

[14] Lassman AB, DeAngelis LM. Brain metastases. Neurol. Clin. 2003;21:1-23.

[15] Barker GH, Orledge J, Wiltshaw E. Involvement of the central nervous system in patients with ovarian carcinoma. Br. J. Obstet. Gynaecol. 1981;88:690-4.

[16] Jia-xin Yang, Keng Shen, Ying Shan, Jing-he Lang, Ming vu, Lina Guo, Hui -fang Huang et al. Seven cases of epitelial ovarian carcinoma with brain metastasis.Chinese medical Sciences Journal 2008;23:19-22.

[17] Lesser GJ. Chemotherapy of cerebral metastases from solid tumors. Neurosurg Clin N Am 1996;7:527-36.

[18] Larson DM, Copeland lj, Mose RP, Malone JM Jr, Gershenson DM, Wharton JTet al. Central Nervous System metastases in epitelial ovarian carcinoma. Obstet Gynecol 1986;68:746-50.

[19] Smith SC, Koh WJ. Palliative radiation therapy for gynaecological malignancies. Best Pract. Res. Clin. Obstet. Gynaecol. 2001;15:265-78.

[20] Wen PY, Black PM, Loeffler JS, Devita VT, Hellman S, Rosenberg SA et al. Treatment of metastatic brain cancer. Principles and Practice of Oncology 6th ed. Philadelphia, Lippincott Williams and Wilkins 2001;2655-70.

[21] Tay SK, Rajesh H. Brain metases from epithelial ovarian cancer. Int J Gynecol Cancer 2005;15:824-9.

[22] Chen YL, Cheng WF, Hsieh CY, Chen CA. Brain metastasis as a late manifestation of ovarian carcinoma. Eur $\mathrm{J}$ Cancer Care 2011;20:44-9.

[23] Amita M, Sudeep G, Rekha W, Yogesh K, Hermant T. Brain metastasis from cervical carcinoma-a case report. Med Gen Med 2005;14:7-26.

[24] Mahmoud-Ahmed AS, Suh JH, Barnett GH. Tumor distribution and survival in six patients with brain metastases from cervical carcinoma. Gynecol Oncol 2001;81:196-9.

[25] Buckner J. Surgery, radiation therapy, and chemotherapy for metastatic tumors to the brain. Curr Opin Oncol 1992;4:518-24.

[26] Patchell RA, Tibbs PA, Walsh JW, Dempsey RJ, Maruyama Y, Kryscio RJ et al. A randomized trial of surgery in the treatment of single metastases to the brain. N Engl J Med 1990;322:494-500.
[27] Lilian $\mathrm{T}$ Gien, Janice S Kwon, David P D’Souza, John S Radwan, Alex Hammond, Akira K Sugimoto et al. Brain metastases from endometrial carcinoma: a retrospective study. Gynecologic Oncology 2004;93:524-8.

[28] Monaco Ed, Kondziolka D, Mongia S, Niranjan A, Flickinger JC, Lunsford LD et al. Management of brain metastases from ovarian and endometrial carcinoma with stereotactic radiosurgery. Cancer 2008;113:2610-4.

[29] Aalders JC, Abeler V, Kolstand P. Recurrent adenocarcinoma of the endometrium: A clinical and histopathological study of 379 patients. Gynecol Oncol 1984;17:85-103.

[30] Wronski M, Zakowski M, Arbit E, Hoskins WJ, Galicich JH. Endometrial cancer metastasis to brain: report of two cases and a review of the literature. Surg Neurol 1993;39:355-9.

[31] Ruelle A, Zuccarello M, Andrioli G. Brain metastasis from endometrial carcinoma:Report of two cases. Neurosurg Rev 1994;17:83-7.

[32] Sewak S, Muggia FM, Zagzag D. Endometrial carcinoma with cerebellar metastasis: A case report and review of the literature. J NeuroOncol 2002;58:137-40.

[33] Mariani A, Webb MJ, Keeney GL, Hematogenous dissemination in corpus cancer. Gynecol Oncol 2001;80:223-8.

[34] Justin C Chura, Robin Marushin, Anders Boyd, Rahel Ghebre, Melissa A Geller, Peter A Argenta et al. Multimodal therapy improves survival in patinets with CNS metastasis from uterin cancers: A retrospective analysis and literature review. Gynecologic Oncology 2007;107:79-85.

[35] Mahmoud-Ahmed AS, Suh JH, Barnett GH, Webster KD, Belinson JL, Kennedy AW et al. The effect of radiation therapy on brain metastases from endometrial carcinoma: A retrospective study. Gynecol Oncol 2001;83:30-9.

[36] N'Kanza AL, Jobanputra S, Farmer P, Lovecchio J, Yelon JA, Rudloff $U$ et al. Central nervous system involvement from malignant mixed Mullerian tumor (MMMT) of the uterus. Arch Gynecol Obstet 2005;273:638.

[37] Wong L, Seen HT, Khootan HS,Low JS, Ng WT, Low JJet al.Combined adjuvant cisplatin and ifosfamide chemotherapy and radiotherapy for malignant mixed mullerian tumors of the uterus. Int J Gynecol Cancer2006;16:1364-9..

[38] Kim JK, Lee SK, Myong HN, Kang YD. Biopsy-proven cerebellar metastasis from a malignant mixed mullerian tumor (MMMT) of the uterus. Eur J Gyaecol Oncol 2009;30: 196-8 
[39] Cormio G, Pellegrino A, Landoni F, Regallo M, Zanetta G, Colombo Aet al. Brain metastases from cervical carcinoma. Tumori 1996;82:394-6.

[40] Ikeda S, Yamada T, Katsumata N, Hida K, Tanemura K, Tsunematu Ret al. Cerebral metastasis in patients with uterin cervical cancer . Jpn. J. Clin. Oncol 1998;28:27-30.
[41] Chura JC, Shukla K, Argenta PA.Brain metastasis from cervical carcinoma.Int. J. Gynecol Cancer 2007;17:141-6.

[42] Ratner ES, Toy E, O'Malley DM, McAlpine J, Rutherford TJ, Azodi $M$ et al. Brain metastases in epithelial ovarian and primary peritoneal carcinoma.Int J Gynecol Cancer 2009;19:856-9.

Citation: Serhat Comert, Mehmet Nur Altınörs. Outcomes of 25 Gynecologic Cancer Patients with Brain Metastasis: A Single Center Experience. ARC Journal of Clinical Case Reports. 2020; 6(2):14-21. doi:dx.doi.org/ 10.20431/2455-9806.0602003.

Copyright: (C) 2020 Authors. This is an open-access article distributed under the terms of the Creative Commons Attribution License, which permits unrestricted use, distribution, and reproduction in any medium, provided the original author and source are credited. 